ESPAÇO TEMÁTICO: TRABALHO, TECNOLOGIAS DA INFORMAÇÃO E COMUNICAÇÃO E

CONDIÇÕES DE VIDA

\title{
Passado, presente e tendências para o futuro das lutas sindicais no Brasil
}

\author{
Rodrigo Fernandes Ribeiro ${ }^{1}$ \\ https://orcid.org/0000-0002-4912-988X \\ ${ }^{1}$ Universidade Federal de Ouro Preto, Instituto de Ciências Sociais Aplicadas, Departamento de Serviço Social, Mariana, \\ MG, Brasil
}

\section{Passado, Presente e Tendências para o Futuro das Lutas Sindicais no Brasil}

Resumo: O sindicalismo no Brasil é determinado pela relação entre capital e trabalho, em que as lutas da classe trabalhadora passaram por avanços e retrocessos. Dentre os avanços, auxiliou na abolição do regime escravista, conquistou uma série de direitos trabalhistas, organizou greves e instituições sindicais. Este artigo busca, a partir da teoria do valor-trabalho e da literatura que analisa o sindicalismo, transitar da gênese ao presente do assalariamento, marcado pela ofensiva do capital que aprofunda o desemprego e a informalidade. Também identifica as tendências para maior precarização das relações e dos contratos de trabalho, assim como a reorganização das lutas sindicais. Conclusivamente, identifica a centralidade da negociação sindical sobre a taxa e as condições de exploração da força de trabalho, assim como a administração do exército industrial de reserva como estratégia do capital.

Palavras-chave: Sindicalismo no Brasil; Precarização do trabalho; Exploração da força de trabalho; Exército industrial de reserva.

\section{Past, present and trends for the future of union struggles in Brazil}

Abstract: Unionism in Brazil is determined by the relationship between capital and labor, in which the struggles of the working class have gone through advances and setbacks. Among the advances, it helped in the abolition of the slave regime, conquered a series of labor rights, organized strikes and union institutions. This article seeks, based on the labor value theory and the literature that analyzes unionism, to move from the genesis to the present of wage-earning, marked by the offensive of capital that deepens unemployment and informality. It also identifies trends towards greater precariousness in relations and employment contracts, as well as the reorganization of union struggles. Conclusively, it identifies the centrality of union negotiation on the rate and conditions of exploitation of the labor force, as well as the administration of the industrial reserve army as a capital strategy.

Keywords: Unionism in Brazil; Precariousness of work; Exploitation of the workforce; Industrial reserve army.

Recebido em: 18.03.2021. Aprovado em: 31.08.2021. Revisado em: 03.09.2021.

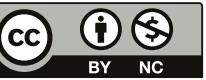

Este é um artigo publicado em acesso aberto (Open Access) sob a licença Creative Commons Attribution NonCommercial, que permite uso, distribuição e reprodução em qualquer meio, sem restrições desde que sem fins comerciais e que o trabalho original seja corretamente citado. 


\section{Introdução}

As transformações no mundo do trabalho estão presentes em toda a sociabilidade em que a relação entre capital e trabalho se constitui como momento predominante. As crises econômicas, sociais e políticas que emergiram nas décadas de 1960 e 1970 aprofundaram os mecanismos que o capital encontrava para sua autorreprodução ampliada, determinadas essencialmente pela lei tendencial da queda da taxa de lucros. A totalidade deste movimento corresponde a uma crise estrutural do capital, em que as personificações do capital buscam resolver os limites da autorreprodução expandindo suas fontes de apropriação do sobretrabalho alheio, em uma lógica expansiva, incontrolável e destrutiva (MÉSZÁROS, 2002). Este movimento amplificou as pressões sobre a força de trabalho disponível em âmbito mundial, fazendo com que o capital e suas personificações empreendessem uma violenta ofensiva reacionária sobre o trabalho, desregulamentando e criando novas modalidades de contratos de trabalho, estagnando ou reduzindo os salários, assumindo o aparelho estatal enquanto protetor exclusivo do capital, utilizando-se conscientemente do exército industrial de reserva global e da repressão institucionalizada sobre o movimento sindical.

Diante dessa realidade, teorias sobre a crise do trabalho e a crise do sindicalismo (ANTUNES, 2006) dominaram a intelectualidade. Neste processo, dirigentes sindicais começaram a encarar as negociações sindicais enquanto condição viável e restrita da luta de classes. Esse processo se deu principalmente nos países de capitalismo central onde a revolução burguesa empreendeu reformas democráticas e nacionais, consubstanciadas em sistemas de seguridade social e legislação trabalhista. Essas teorias incorreram em dois erros: generalizar as condições de trabalho e de sindicalização de setores econômicos da indústria de transformação para todos os demais setores e, também, generalizar a condição do proletariado dos países capitalistas centrais para os países de capitalismo dependente.

Analisar o sindicalismo no Brasil, portanto, é uma tarefa que necessita se debruçar sobre o padrão de desenvolvimento capitalista que predomina neste país dependente e com sua burguesia associada ao imperialismo (FERNANDES, 1975). Além disso, precisa identificar a gênese do regime escravista mercantil, a regulação tardia das relações e dos contratos de trabalho, o papel da ampliação do proletariado e de suas lutas nos anos 1980 com o chamado novo sindicalismo e as transformações hodiernas que vão apontando tendências de extensão da precarização para amplo contingente da classe trabalhadora.

A organização deste artigo é composta por essa introdução, uma seção que retoma os fundamentos da teoria valor-trabalho em Karl Marx e Friederich Engels, duas seções que buscarão responder as questões do parágrafo acima, assim como as considerações finais.

\section{Os fundamentos do assalariamento e das lutas sindicais: a teoria do valor-trabalho.}

O conteúdo da ação sindical está inscrito na relação entre os proprietários dos meios de produção, a burguesia, e os detentores da força de trabalho, o proletariado. Entre os dois se estabelece um contrato do qual as partes são livres para vender e comprar a mercadoria força de trabalho. A regulação deste processo se realiza pela luta de classes, expressas nas dimensões sociais, culturais, políticas e jurídicas. Essa síntese pode parecer simplista no sentido da apreensão das formas, mas em seu conteúdo ela se fundamenta na teoria do valor-trabalho.

As duas personificações apresentadas acima, do capital e do trabalho, foram produzidas pelas lutas de classes, que tiveram na revolução industrial e burguesa a sua gênese. A hegemonia da dominação burguesa foi possível com as lutas que se realizaram na transição do modo de produção feudal para o capitalista, que se hegemonizou com a desapropriação progressiva dos artesãos e dos camponeses, de seus instrumentos de trabalho, meios de produção e matérias-primas. Esse processo do qual emergiu o capitalismo como modo de produção predominante se deu por diferentes fases e organizações da produção, descritas por Marx (2013) em $O$ Capital, como a cooperação, a manufatura e a maquinaria. Essa última, demarcada pela introdução das máquinas em grande escala, constituiu-se em instrumento de disciplinamento, intensificação, ampliação da jornada e redução do valor da força de trabalho. Para Marx (2013, p. 508), “[...] ela se converte na arma mais poderosa para a repressão das periódicas revoltas operárias, greves, etc. contra a autocracia do capital”. 
A lei do valor-trabalho é elemento essencial no processo de negociação entre capitalistas e trabalhadores, já que o assalariamento corresponde ao pagamento do trabalho necessário, o valor da força de trabalho que se expressa em meios de subsistência necessários para a sua reprodução - valores de uso úteis como alimentação, moradia, vestuário e outros, de acordo com o "elemento histórico e moral" (MARX, 2013, p. 246) que se constituí em determinado país ou setor econômico.

Como o valor da força de trabalho corresponde a um quantum de meios de subsistências necessários para um tempo de uso específico de sua reprodução, a condição sui generis desta mercadoria se dá pela possibilidade de que o tempo de uso possa ser maior do que o tempo pelo qual é necessária a reprodução dessa força de trabalho. Este se constitui em um tempo de trabalho excedente não pago ${ }^{1}$, em que "ele gera mais valor, que, para o capitalista, tem todo o charme de uma criação a partir do nada" (MARX, 2013, p. 293). A mais-valia então surge deste uso excedente do trabalho, que pode ser extraído também da intensificação do trabalho em uma mesma jornada, exigindo mais trabalho para produção de mais mercadorias em um mesmo tempo. Esse trabalho excedente é o objeto do capitalista, a fonte da exploração sobre a força de trabalho.

A ação sindical interage sobre a negociação entre capitalista e trabalhador, podendo a união destes trabalhadores reaver parte do trabalho excedente não pago ou os capitalistas expandirem a mais-valia extraída. Esse processo se consubstancia na negociação do salário, melhores condições de trabalho, equipamentos de segurança, qualificação, dentre tantas outras questões que podem incorporar salários indiretos ou benefícios que valorizem mais a força de trabalho. Em síntese, a negociação sindical tem como objeto central a taxa e as condições de exploração do trabalho assalariado. Por isso que a greve, instrumento de luta por excelência da classe trabalhadora, caracteriza-se pela paralisação da produção, evidenciando o papel central que o trabalho vivo tem na produção de mercadorias e em sua valorização.

Em A situação da classe trabalhadora na Inglaterra, Engels expôs a reação desta classe mediante a sujeição que se estabelecia nos primórdios do capitalismo. Para ele, “[...] o operário só pode salvar sua condição humana pelo ódio e pela rebelião contra a burguesia" (ENGELS, 2010, p. 247). Esse ódio teria sido explicitado em diferentes fases de revoltas dos operários, que seguiriam de perto o desenvolvimento da indústria, sendo os crimes e a rebelião contra as máquinas e seus inventores as primeiras expressões. Em sequência, estaria a organização em associações de auxílio mútuo, a constituição das Trade Unions e a proliferação das greves, que corresponderiam à primeira fase organizativa do proletariado. Os trabalhadores necessitavam expressar a sua insatisfação com aquela situação e "suprimir a concorrência" entre estes, mesmo que estes não conseguissem suprimir as relações de exploração. Neste processo eles descobririam que "a lei é um látego produzido pelo burguês" (ENGELS, 2010, p. 261).

O quarto e último momento seria a organização em um partido político. No caso da Inglaterra, o movimento da Carta do Povo, o Cartismo, seria "a forma condensada de oposição à burguesia", mas que ainda não se distinguia da pequena burguesia radical e que só com o tempo teria se fundido com o socialismo e se tornado "um movimento puramente operário, depurado de todos os elementos burgueses" (ENGELS, 2010, p. 262).

Engels chamou a atenção para o fato de que as greves são as principais expressões da guerra entre a burguesia e o proletariado, que apresentavam em seu fazer o potencial consciente desta luta, mas que não suprimiam os fundamentos desse antagonismo. Para Engels (2010, p. 258 - grifos nossos):

Essas greves são em geral pequenas escaramuças de vanguarda e, às vezes, combates mais importantes; não solucionam nada definitivamente, mas são a prova mais segura de que se aproxima o confronto decisivo entre o proletariado e a burguesia. Elas são a escola de guerra na qual os operários se preparam para a grande batalha, agora inevitável; são os pronunciamentos das distintas categorias de operários, consagrando sua adesão ao grande movimento proletário.

1 A distinção entre uso e valor da força da força de trabalho é marcante nesta mercadoria. Marx assim desenvolve essa relação: "O valor da força de trabalho e sua valorização no processo de trabalho são, portanto, duas grandezas distintas. [...] A circunstância na qual a manutenção diária da força de trabalho custa apenas meia jornada de trabalho, embora a força de trabalho possa atuar por uma jornada inteira, e, consequentemente, o valor que ela cria durante uma jornada seja o dobro de seu próprio valor diário - tal circunstância é, certamente, uma grande vantagem para o comprador, mas de modo algum uma injustiça para com o vendedor" (MARX, 2013, p. 270). 
Marx expôs os limites da ação sindical em Congresso da Internacional Socialista de 1865, em relatório de confronto aberto contra as concepções que criticavam as lutas dos trabalhadores. Na terceira resolução de seu texto, este expressa, em poucas linhas, a síntese dessa dialética potencial/limite do movimento sindical:

Os Sindicatos (Trade Unions) funcionam bem como centros de resistência contra as investidas do capital. Fracassam parcialmente por um uso não-judicioso do seu poder. Fracassam geralmente por se limitarem a uma guerra de guerrilha contra os efeitos do sistema existente, em vez de simultaneamente tentarem muda-lo, em vez de usarem as suas forças organizadas como uma alavanca para a emancipação final da classe operária, isto é, para a abolição última do sistema de salários (MARX, 2008, p. 90).

Nesta escola de guerra, a luta pela reposição de parte da mais-valia expropriada pode representar uma das bandeiras imediatas e econômicas da classe trabalhadora, mas o objetivo principal seria a supressão da concorrência entre os trabalhadores e a supressão da relação de exploração pelo qual estes estão submetidos pelos capitalistas. Engels reconhece que essa relação subordinada pode ser rompida assim que a união entre os despossuídos não permita mais essa contradição mediada pela propriedade privada moderna. Engels (2010, p. 253) foi categórico ao afirmar que "[...] uma vez suprimida a concorrência entre os operários, uma vez que todos se decidam a não mais deixar-se explorar pela burguesia, o reino da propriedade chegará ao fim".

Apesar da teoria do valor-trabalho ter sido desenvolvida no século XIX, os fundamentos do trabalho como produtor de valor e de mais-valia persistem e passam por metamorfoses que alteram as formas pela qual os contratos são feitos, pelo qual a tecnologia e a gestão dos processos de trabalho incidem sobre ritmos, movimentos e ações dos trabalhadores e, principalmente, como que a ideologia do capital produz valores e padrões subjetivos que são internalizados pela classe trabalhadora (ANTUNES, 2018; VALENTIN, PERUZZO, 2017).

A gênese e o desenvolvimento deste movimento na realidade brasileira são o objeto das próximas seções, buscando identificar a articulação da totalidade da luta de classes neste particular território.

\section{Três momentos sobre a constituição da classe trabalhadora no Brasil}

Sob a determinação fundante da lei do valor-trabalho e do processo de acumulação capitalista, encontram-se uma série de múltiplas sobredeterminações de fundamental interesse para a análise da composição heterogênea da classe trabalhadora. Para fins de síntese do passado do trabalho no Brasil, este artigo resgata três momentos essenciais.

Antes de entrar nestes momentos é importante retomar, de antemão, que este país, assim como toda a América, sofreu os influxos do processo de colonização, o neocolonialismo praticado com a independência formal e o capitalismo dependente (FERNANDES, 1975). Deste último, a particularidade aqui se estabeleceu com o controle externo da produção e reprodução capitalista, atendendo aos interesses imperialistas e aos lucros dos monopólios internacionais.

O primeiro momento aqui destacado, de constituição da classe trabalhadora, se dá pelo passado secular estabelecido sobre o regime do escravismo mercantil. A imposição da coerção violenta extraeconômica sobre os povos originários e os cativos africanos, o predomínio da monocultura da plantagem para atendimento das necessidades econômicas da emergente Revolução Industrial na Europa e a constituição de uma classe dominante sem projeto nacional e soberano, são elementos que até hoje se rebatem sobre a constituição da classe trabalhadora ${ }^{2}$. A tardia abolição da escravatura e a manutenção de condições precárias de trabalho e vida dos então trabalhadores libertos são determinantes para a atual estrutura racial desigual e hierárquica do trabalho. Não só não houve reparações por anos de opressão, como estes trabalhadores não foram devidamente incluídos na ordem social competitiva do capitalismo nascente do início do século XX.

Com relação aos poucos trabalhadores livres assalariados do século XIX, restritos às grandes cidades do país e a algumas poucas categorias, estes tiveram as suas primeiras expressões de organização sindical com

2 Sobre a questão da colonização, destacamos Jacob Gorender (2016), com a ressalva da não concordância com a afirmação de que o escravismo colonial seria um modo de produção, e Caio Prado Jr (2011), com a ressalva da não concordância de que o Brasil já seria capitalista desde o período colonial. 
as sociedades de auxílio-mútuo e as primeiras greves. Somente no século $\mathrm{XX}$, com as primeiras indústrias e revoluções comunistas pelo mundo, que os trabalhadores construíram as primeiras confederações sindicais e expandiram-se os sindicatos livres (MATOS, 2009).

O segundo momento refere-se ao período do qual o padrão de acumulação capitalista exigiu a industrialização de setores importantes. A chamada Revolução de 1930, com a alçada de Getúlio Vargas ao poder, fez com que a estrutura sindical corporativa de Estado fosse constituída pari passu com a estrutura de proteção social trabalhista encarnada na Consolidação das Leis Trabalhistas (CLT) de 1943³. Este movimento, assim como o foi da abolição da escravatura, representava o alcance de reivindicações legítimas da classe trabalhadora, ao mesmo tempo em que atendia ao padrão de acumulação da burguesia industrial nativa e do imperialismo. Ou seja, direitos trabalhistas, tais como registro de carteira assinada e férias, dentre outros, foram possíveis ao mesmo tempo em que os antigos sindicatos livres passaram a serem sindicatos outorgados pelo Estado.

A magnitude de toda essa estrutura sindical e o que este momento representa para a classe trabalhadora hodierna é que ela continua determinando a regulação do trabalho no Brasil, ainda que houvesse momentos de extensão destes direitos, como na Constituição Federal de 1988, e retrocessos, representados pela última reforma trabalhista de 2017.

E, para fechar, o terceiro momento não poderia deixar de ser representado pelo influxo da concretização da revolução burguesa no Brasil, com a aceleração do padrão monopolista instituído no período da ditadura civil-militar iniciada em 1964. Este regime autoritário permitiu o controle violento da classe trabalhadora, reprimindo qualquer manifestação dentro da ordem, incluindo aqui a atividade sindical. Além disso, representou uma saída necessária do imperialismo e dos monopólios para a intensificação da exploração da força de trabalho no Brasil. A legislação que impedia a negociação dos reajustes salariais e a que criou o Fundo de Garantia por Tempo de Serviço (FGTS), destituindo na prática uma espécie de estabilidade que os trabalhadores do setor privado tinham, foram as principais medidas que correspondem aos fundamentos da relação capital/ trabalho, extraindo o máximo possível de trabalho excedente não pago, fonte de lucros para a burguesia local e estrangeira ${ }^{4}$.

Este momento não poderia deixar de ser, também, um momento determinante pelo qual o proletariado protagonizaria a potente reorganização da classe trabalhadora da década de 1980. Os metalúrgicos do $\mathrm{ABC}$ paulista tornaram-se exemplos de resistência e constituição de uma classe em si, com as poderosas greves dos anos 1978-1980. Florestan Fernandes (1995, p. 172), destacou esse processo:

Ao enfrentar a ditadura e ao desobedecê-la, o proletariado vergou o arco do despotismo burguês - mas assustou todo o sistema de poder capitalista, em suas ramificações nacionais e internacionais, e não conquistou outra coisa além do espaço político que abocanhou para lutar como classe plenamente constituída, que exige sua autonomia como e enquanto classe e a liberdade para travar tal luta em todas as direções necessárias.

Este movimento, conhecido como novo sindicalismo, deu sustentação para uma onda que contagiou metalúrgicos, petroleiros, bancários, funcionários públicos e demais categorias de trabalhadores, em numerosas greves e a constituição do instrumento da Central Única dos Trabalhadores (CUT), em 1983. Destaca-se também os rebatimentos destes movimentos na extensão dos direitos trabalhistas para os assalariados rurais, outros direitos trabalhistas e a extensão dos sistemas de proteção social, consolidados na Constituição Federal de 1988.

Os posteriores desdobramentos da luta de classes no Brasil, como o avanço da ofensiva ideológica e concreta do capital sobre os processos, contratos e regulação do trabalho, principalmente na década de 1990, foram sentidos até mesmo na organização destes trabalhadores. Para fins de avanço neste debate, partimos agora para a atualidade destes movimentos e tendências que se apontam.

3 As referências aqui sobre as lutas dos trabalhadores em Marcelo Badaró Matos (2009), e a estrutura sindical corporativa de Estado, que constituiu o sindicato oficial, com investidura estatal, unicidade sindical e contribuições compulsórias, ver em Armando Boito $\operatorname{Jr}(1991)$.

4 Sobre o que fez o regime ditatorial civil-militar inaugurado em 1964, Antonio Luigi Negro (1999, p. 18) afirma: "As medidas do novo regime tiveram um caráter fortemente pró-patronal, sendo elas: (1) desmonte da legislação existente sobre estabilidade no emprego com a instauração do FGTS; (2) lei de remessa de lucros; (3) a lei antigreve 4330 e; (4) o rígido controle estatal sobre os salários". 


\section{O presente e o futuro do trabalho e do sindicalismo no Brasil}

No século XXI as transformações da tecnologia aceleraram a informação, expandiram consideravelmente a rede mundial de computadores e constituíram grandes monopólios no campo informacional e outros nichos do setor de serviços. Muitas dessas tecnologias dinamizaram a produção, a valorização e a realização do valor ${ }^{5}$.

Como afirmado nas seções anteriores, a luta de classes dinamiza as relações entre capital e trabalho, os contratos e condições de trabalho, as negociações sindicais, dentre tantos outros aspectos. As tendências de elevação da composição orgânica do capital e consequente queda das taxas de lucro, devido à corrida tecnológica que a concorrência capitalista produz, imprimem um acirramento e explosão violenta das personificações do capital sobre o trabalho. Mantêm-se como contratendências, ou como Marx denominou de medidas contrarrestantes do capital ${ }^{6}$, o aumento do grau de exploração do trabalho com a extensão e a intensificação das jornadas de trabalho, as ações para compressão do salário abaixo de seu valor, assim como, e principalmente, a administração de um exército industrial de reserva ${ }^{7}$ que tem como objetivo a manutenção de alta oferta de força de trabalho no mercado, que intimide as sublevações da classe trabalhadora (MARX, 2017).

As principais tendências globais de flexibilização dos contratos de trabalho apresentaram-se terrivelmente ofensivas no Brasil. A década de 2000 terminou com menores taxas de desemprego, mas com a proliferação dos mecanismos de terceirização, aperfeiçoamento de contratos precários, aumento do número de trabalhadores informais e com muitas vagas criadas com salários reduzidos. Esses mecanismos aprofundaram a pulverização de tipos de contratos de trabalho e dos sindicatos, criando uma atmosfera de identificação coletiva mais difícil da classe trabalhadora, que pudesse fazer frente à concorrência do capital reunido ${ }^{8}$. Antunes e Graça Druck (2018, p. 263) expõe uma síntese sobre as diferentes dimensões da terceirização como principal fio condutor da precarização:

Em síntese, a terceirização é o fio condutor da precarização do trabalho no Brasil. Constitui-se em um fenômeno onipresente em todos os campos e dimensões do trabalho, sendo uma prática de gestão/ organização/controle que discrimina e, ao mesmo tempo, é uma forma de contrato flexível e sem proteção trabalhista. É também sinônimo de risco de saúde e de vida, responsável pela fragmentação da identidade coletiva dos trabalhadores, com a intensificação da alienação e da desvalorização do trabalho humano, assim como é um instrumento de pulverização da organização sindical, que incentiva a concorrência entre os trabalhadores e seus sindicatos. Ela ainda cobre com um 'manto de invisibilidade' os trabalhadores nela enquadrados, como facilitadora do descumprimento da legislação trabalhista, como forma ideal para o empresariado não ter limites (regulados pelo Estado) no uso da força de trabalho e da sua exploração como mercadoria.

A conjuntura socioeconômica dos anos 2000 no Brasil foi dinamizada com os aumentos do salário-mínimo na base da pirâmide social e por políticas de transferência de renda, como o Programa Bolsa Família. Essa realidade foi coetânea com o aumento da produção e do preço das commodities agrominerais, que imprimiu um crescimento econômico apropriado pelos monopólios da agroindústria, do extrativismo mineral e do setor financeiro. Outros setores econômicos surfaram neste crescimento, destacando-se aqui o setor de serviços e a construção civil. Em geral, com as vagas de emprego criadas no mercado, principalmente no setor de serviços,

5 As atuais transformações do mundo do trabalho incidem na esfera da produção, com a implementação da Indústria 4.0 e a internet das coisas, intensificando a produção de valor nas indústrias de transformação. Há também uma incidência muito grande na esfera da reprodução, destacando-se aqui o setor de serviços, que não só atuam no sentido da redução da rotação do capital, como passam a ser setor econômico que emprega muita força de trabalho com menor qualificação, mediada por plataformas e inovações tecnológicas que subordinam violentamente estes trabalhadores (ANTUNES, 2018).

6 Além destas, Marx também identifica o barateamento dos elementos do capital constante, o comércio exterior e o aumento do capital acionário (MARX, 2017).

7 Essa categoria é central na análise que Marx faz sobre a lei geral da acumulação capitalista. Denominada também como população trabalhadora excedente ou superpopulação relativa, essa se converte em "alavanca da acumulação capitalista, e até mesmo numa condição de existência do modo de produção capitalista” (MARX, 2013, p. 707).

8 Muitos estudos aprofundaram este momento, criticando a ofensiva sobre os contratos de trabalho, a representação sindical, a manipulação ideológica, dentre outros. Destacamos aqui Druck (2011), Pochmann (2012) e Antunes (2018). 
houve a redução do exército industrial de reserva - diminuição do desemprego e aumento da formalização -, porém, com vagas em setores que pagavam salários muito reduzidos9.

Tal realidade caracterizou as relações de produção e reprodução no Brasil até quase metade da década de 2010. Em 2013 grandes mobilizações de rua, nas chamadas "Jornadas de Junho", empunhavam a insatisfação com as políticas públicas, destacando-se a mobilidade urbana. Neste mesmo ano se inicia um novo ciclo de recorde de greves e horas paradas, assim como o aumento destas com reivindicações propositivas, que vão até o ano de $2016^{10}$. A expansão dessas greves para as empresas privadas e nos setores de serviços demonstra o quanto à precarização crescente pressionou a exigência de mais mobilização, expressando uma situação da qual estes setores partem para lutas mais radicalizadas com a finalidade de se reaver parte da riqueza expropriada. É sintomática a expressividade das greves neste período, que só puderam ser realizadas em suas reivindicações de defesas das condições existentes ou de proposições de reajustes salariais, dentre outros benefícios, porque a oferta da mercadoria sui generis, força de trabalho, era reduzida, pressionando os trabalhadores para o enfrentamento com um oponente com capacidade reduzida de promover demissões em massa e uso do exército industrial de reserva.

Após 2015, os retrocessos na proteção e regulação do trabalho foram intensos. Medidas de austeridade fiscal no segundo governo de Dilma Rousseff reduziram direitos como seguro-desemprego, pensão sobre morte e auxílio-doença. No governo de Michel Temer, o acirramento se estabeleceu por contrarreformas de vulto, destacando-se aqui a Emenda Constitucional 95/2016 de congelamento dos gastos sociais e investimentos públicos e as contrarreformas trabalhistas. Fecha esse ciclo de ofensivas, até então, a experiência do governo de extrema-direita de Jair Bolsonaro, que tem como principal marca destrutiva a aprovação da chamada Reforma da Previdência, em 2019.

A análise aqui se detém nas contrarreformas trabalhistas de 2017, que concretizaram uma reestruturação do Brasil na divisão internacional do trabalho, em que os capitais estrangeiros e locais pressionaram por uma profunda desregulamentação das já precárias relações de trabalho. Em abril de 2017, a aprovação da Lei $n^{\text {o }} 13.429$ (BRASIL, 2017), que estendia a possibilidade da terceirização para as atividades-fim, não só as atividades-meio como vigorava até então, atingiu a representatividade e a luta sindical de muitos trabalhadores. Agora, se ainda se preservavam os vínculos de categorias inteiras de trabalhadores para com a empresa principal, com a aprovação desta lei a pulverização de empresas contratantes fortalecia ainda mais a posição do capital frente o trabalho.

A escalada do capital atingiu mais um patamar de ataques com a aprovação da Lei n ${ }^{\circ} 13.467$ (BRASIL, 2017a), de novembro do mesmo ano. A chamada Reforma Trabalhista alterou mais de 120 artigos da CLT, atingindo alguns dos pilares centrais da proteção do trabalho no Brasil, destacando aqui a prevalência do negociado frente o legislado, que fragilizou a grande maioria de categorias de trabalhadores pelo Brasil. Além dessa medida, outras flexibilizaram a jornada de trabalho, permitiram que gestantes trabalhassem em ambientes insalubres, dentre outras. Outra mudança muito profunda, que responde à transformações já realizadas em outras partes do mundo ${ }^{11}$, foi a criação do contrato de trabalho intermitente, cuja relação contratual permite

9 Márcio Pochmann (2012), em estudo crítico sobre a chamada nova classe média, identificou que dentre as vagas criadas no mercado de trabalho entre 2000 e 2010, quase que a integralidade (mais de 90\%) pagava até um salário mínimo e meio, assim como ocorrera a extinção de muitas vagas que pagavam acima de cinco salários mínimos.

10 Os relatórios dos balanços de greves do Departamento Intersindical de Estudos e Estatísticas Socioeconômicas - DIEESE (2019; 2020) identificam que entre 1998 e 2011 o número de greves em todo o território nacional teve como limite um pouco mais de 500 ocorrências por ano. Em 2012 o número chegou a quase 900 e durante o ciclo de ascensão das greves, 2013 a 2016, em média ocorreram 2.000, com redução progressiva até as 1.118 registradas em 2019. Com relação às horas paradas houve estabilidade de uma média de 20.000 horas de 1998 a 2008, crescimento progressivo desde então até o número limite de 141.000 horas em 2016, reduzindo a partir daí até chegar o número de 44.650 horas paradas em 2019. Com relação às greves que tinham caráter propositivo - que podem também ser, em uma mesma situação, defensivas e de protesto -, que não chegavam a 300 casos de 1998 a 2008, tiveram o ápice em 2013 com o número de 1.180 ocorrências, reduzindo posteriormente até chegar às 294 greves propositivas em 2019

11 Muito inspirada no zero hour contract, que o Reino Unido instituiu no começo do século XXI, em que "os contratos não têm determinação de horas" (ANTUNES, 2018, p. 34). 
que empregadores possam até não acionar os trabalhadores em mês inteiro e estes não recebam qualquer remuneração ${ }^{12}$.

Destas duas contrarreformas e de tantas outras ofensivas neste curto período de 2015 a 2020, os resultados no mercado de trabalho foram, até março de 2020 , de grande desemprego e informalidade ${ }^{13}$. No primeiro trimestre de 2020, a Pesquisa Nacional de Amostra por Domícilio (PNAD-Contínua, 2020) do Instituto Brasileiro de Geografia e Estatística (IBGE) registrou a taxa de desemprego em 12,2\%, um universo de mais de 12,9 milhões de trabalhadores, compreendendo somente aqueles que são considerados dentro da força de trabalho (IBGE, 2020). Além destes, os trabalhadores que não eram considerados pertencentes à força de trabalho equivaliam a 67,3 milhões de pessoas, assim como os chamados desalentados, que gostariam de trabalhar mas não se motivaram para procurar emprego, compunham 4,9 milhões de trabalhadores.

Analisando apenas os trabalhadores no campo da informalidade, estes equivaliam a $39,9 \%$ da força de trabalho ativa no mesmo período, ou 36,8 milhões de pessoas. Trata-se de um universo gigantesco de trabalhadores que não possuem qualquer proteção social, que não podem ficar doentes, que não podem paralisar suas atividades por qualquer motivo - e a pandemia demonstrou que há situações imponderáveis - e que não contribuem com a previdência social, em sua grande maioria (PNAD-Contínua, 2020).

Neste contexto de grande desemprego e informalidade, o sindicalismo de Estado continuou presente na realidade. Não só a investidura e a unicidade sindical continuam presentes, como a gigantesca pulverização ainda é realidade, em um contexto do qual existem mais de 16.922 sindicatos registrados no país em 2020, sendo que destes 11.626 são os sindicatos de trabalhadores (MINISTÉRIO DA JUSTIÇA E SEGURANÇA PÚBLICA, 2020). Contudo, neste processo o sindicalismo acabou perdendo poder de fazer frente à concorrência contra o capital com o aumento do exército industrial de reserva, desempregados, desalentados e informais. A concorrência entre estes se intensificou, fazendo com que seu poder de pressão se reduzisse e, em muitas situações, a luta se redirecionasse para a manutenção dos empregos já existentes. Além disso, falhou nas táticas que pudessem reunir a classe trabalhadora na luta contra os ataques ao mercado de trabalho e às contrarreformas trabalhista e previdenciária. O papel dessa luta unificada caberia às centrais sindicais que reúnem sindicatos de base, federações e confederações de trabalhadores. Contudo, o corporativismo e a pulverização das centrais sindicais (GALVÃO, 2009), foram prejudiciais na luta pelo fortalecimento das lutas específicas e gerais da classe trabalhadora.

Outras medidas que foram aprovadas pela reforma trabalhista de 2017, que se referenciam à regulamentação da organização sindical, vieram para dificultar a relação com as bases sindicais e o local de trabalho, como a desobrigação de que a escolha das representações por local de trabalho e as rescisões de contrato fossem acompanhadas pelo sindicato. $\mathrm{O}$ teor geral dessas medidas acompanhou as demandas das principais confederações e federações patronais, que propunham parte destas alterações desde a década de 1990 (SILVA, 2019). Até mesmo uma das medidas que isoladamente poderia ser identificada como progressista, a eliminação da compulsoriedade do imposto sindical, não proporcionou ganhos organizativas para a classe trabalhadora. Pelo contrário, mantendo os outros dois pilares da estrutura sindical corporativa do Estado, a outorga da carta sindical e a unicidade na lei, os fundamentos do controle estatal sobre a atividade sindical mantiveram os principais controles e até mesmo enfraqueceram sindicatos combativos que não conseguiram outras formas de arrecadação de recursos.

Para finalizar, é preciso retomar o pressuposto de que as lutas sindicais têm como principal determinação a lei do valor-trabalho. Dependendo das condições ao qual são submetidas, seja de uma categoria de trabalhadores com grande experiência sindical e qualificação específica, seja de outra categoria com nenhuma experiência e

12 O resultado desta modalidade, nos dois primeiros anos de existência, foi de um contingente de trabalhadores que não conseguiam receber nem mesmo um salário-mínimo e de tantos outros que não receberam nada no mês. No breve artigo analítico, Vitor Filgueiras e José Dari Krein (2020, n.p.) identificam que a figura dessa modalidade de contrato intermitente criada pela Reforma poderia ser considerada como um "desempregado com carteira assinada", ao apresentar números tais como o de que dos " 156 mil empregados ativos ao final de 2019 [referente ao mês de dezembro], 85 mil (54,7\% de todos os intermitentes) aparecem com salários zerados".

13 Este artigo não analisa os impactos sobre o trabalho e a classe trabalhadora após março de 2020, quando a crise sanitária da pandemia de Covid-19 incide diretamente na produção e reprodução do valor, agudizando os efeitos deletérios sobre a força de trabalho que estava sendo utilizada até então, os desempregados e os trabalhadores na informalidade. 
menor exigência de qualificação, quando o valor de sua força de trabalho se reduz ou alguma transformação em seu processo de trabalho se realiza, a explosão e organização do movimento podem se acelerar. O conturbado ano de 2020 mostrou que esse potencial pôde partir de qualquer extremo da relação de proteção trabalhista: em fevereiro deste ano a greve nacional dos petroleiros conseguiu mobilizar e pressionar contra a aceleração do processo de privatização e demissões de trabalhadores (APÓS CONQUISTAR..., 2020); em julho, com o aumento da oferta de trabalho para entregadores de mercadorias mediadas por aplicativos, que reduziu consideravelmente o valor de suas remunerações, uma inédita greve de um dia apresentou essa mobilização nas grandes cidades do país e colocou essa categoria na cena histórica da classe trabalhadora (BRASIL DE FATO, 2020).

\section{Considerações finais}

Do objeto que aqui foi evidenciado, é preciso enfatizar as duas determinações que continuam prevalecendo no âmbito das lutas sindicais. A primeira é referente à mediação na negociação das condições e da taxa de exploração da força de trabalho. Os limites são imensos, não só pelas reivindicações meramente econômicas, mas também pelo fato de que os direitos trabalhistas nunca foram de acesso à maioria da classe trabalhadora brasileira. Como evidenciado neste artigo, os últimos anos têm expandido a precarização do trabalho para diversas categorias. Contudo, de acordo com a teoria do valor-trabalho, as potencialidades dessas lutas se dão no enfrentamento efetivo e na tomada de consciência de que a superação da exploração se dará em uma etapa superior.

A segunda determinação reforça a primeira. O Estado burguês e o capital administram a existência de um exército industrial de reserva. Os curtos períodos de crescimento econômico, em que o desemprego diminui, cria limites na manutenção das taxas de lucro, demandando mais trabalhadores e fortalecendo, ao mesmo tempo, as reivindicações deste por menor extração de mais-valia. Por isso é que, nestes últimos anos, há uma série de políticas estruturais no sentido de controlar essa população excedente, seja aquele contingente desempregado, seja o contingente na informalidade ou duramente precarizado. A luta de toda a classe trabalhadora exige essa organização coletiva, para destronar a concorrência entre os vendedores de força de trabalho e fazer frente à concorrência perante o capital.

\section{Referências}

ANTUNES, R. Adeus ao Trabalho: ensaios sobre as metamorfoses e a centralidade do mundo do trabalho. $11^{\circ}$ ed. Campinas-SP; Editora da UNICAMP, 2006.

ANTUNES, R. O privilégio da servidão: o novo proletariado de serviços na era digital. São Paulo; Boitempo, 2018.

APÓS CONQUISTAR abertura de diálogo com a Petrobras, FUP indica suspensão da greve. Redação RBA, São Paulo, 20 fev. 2020. Disponível em: https://www.redebrasilatual.com.br/trabalho/2020/02/apos-conquistar-abertura-de-dialogo-com-a-petrobras-fup-indicasuspensao-da-greve/ Acesso em: 02 dez. 2020.

BOITO JR, A. O sindicalismo de Estado no Brasil: uma análise crítica da estrutura sindical. São Paulo: Hucitec, 1991.

BRASIL. Lei no 13.429, de 31 de março de 2017. Altera dispositivos da Lei no 6.019, de 3 de janeiro de 1974, que dispõe sobre o trabalho temporário nas empresas urbanas e dá outras providências; e dispõe sobre as relações de trabalho na empresa de prestação de serviços a terceiros. Brasília, DF: Presidência da República, [2017]. Disponível em: http://www.planalto.gov.br/ccivil_03/_Ato20152018/2017/Lei/L13429.htm Acesso em: 02 dez. 2020.

BRASIL. Lei $n^{\circ}$ 13.467, de 13 de julho de 2017. Altera a Consolidação das Leis do Trabalho (CLT), aprovada pelo Decreto-Lei ${ }^{\circ}$ 5.452, de $1^{\circ}$ de maio de 1943, e as Leis $n^{\circ} 6.019$, de 3 de janeiro de 1974, 8.036, de 11 de maio de 1990, e 8.212, de 24 de julho de 1991, a fim de adequar a legislação às novas relações de trabalho. Brasília, DF: Presidência da República [2017a]. Disponível em: http://www.planalto.gov.br/ccivil_03/_ato2015-2018/2017/lei/L13467.htm. Acesso em: 02 dez. 2020.

CARVALHO, I. Superexplorados em plena pandemia, entregadores de aplicativos marcam greve nacional. Brasil de Fato, São Paulo, 16 jun. 2020. Disponível em: https://www.brasildefato.com.br/2020/06/16/superexplorados-em-plena-pandemia-entregadores-deaplicativos-marcam-greve-nacional Acesso em: 02. dez. 2020.

DIEESE. Balanço das greves de 2018. Estudos e Pesquisas. nº 89, abril de 2019. Disponível em: https://www.dieese.org.br/ balancodasgreves/2018/estPesq89balancoGreves2018.html. Acesso em: 20 jul. 2020. 
DIEESE. Balanço das greves de 2019. Estudos e Pesquisas. no 93, maio de 2020. Disponível em: https://www.dieese.org.br/ balancodasgreves/2019/estPesq93balancoGreves2019.pdf. Acesso em: 02 dez. 2020.

DRUCK, G. Trabalho, precarização e resistências: novos e velhos desafios? Caderno CRH, Salvador, v. 24, n. spe 01, p. $37-57,2011$. ENGELS, F. A situação da classe trabalhadora na Inglaterra. São Paulo; Boitempo, 2010.

FERNANDES, F. Capitalismo dependente e classes sociais na América Latina. $2^{\circ}$ Ed. São Paulo: Zahar Editores, 1975.

FERNANDES, F. Em busca do socialismo: últimos escritos e outros textos. São Paulo; Xamã, 1995.

FILGUEIRAS, V.; KREIN, J. D. Reforma criou a figura do "desempregado com carteira assinada" no Brasil. Coluna de Leonardo Sakamoto. Uol, São Paulo, 08 dez. de 2020. Disponível em: https://noticias.uol.com.br/colunas/leonardo-sakamoto/2020/12/08/ desempregado-de-carteira-assinada-e-o-fruto-da-flexibilizacao-trabalhista.htm. Acesso em: 11 dez. 2020.

GALVÃO, A. A reconfiguração do movimento sindical no governo Lula. Revista Outubro, nº 18, 2009.

GORENDER, J. O escravismo colonial. São Paulo: Expressão Popular, 2016.

MARX, K. Salário Preço e Lucro. $5^{\circ}$ edição, São Paulo; Editora Centauro, 2008.

MARX, K. O Capital - Livro I. São Paulo: Boitempo, 2013.

MARX, K. O Capital - Livro III. São Paulo; Boitempo, 2017.

MATOS, M. B. Trabalhadores e sindicatos no Brasil. São Paulo; Expressão Popular, 2009.

MÉSZÁROS, I. Para além do capital: Rumo a uma teoria da transição. São Paulo: Boitempo, 2002.

MINISTÉRIO DA JUSTIÇA E SEGURANÇA PÚBLICA. Dados Abertos/ Estatísticas. 2020. Disponível em: https://www.justica. gov.br/seus-direitos/registro/dados-abertos-estatistica Acesso em: 30 nov. 2020.

NEGRO, A. L. Nas origens do Novo Sindicalismo: O Maio de 59, 68 e 78 na Indústria Automobilística. In: RODRIGUES, I. J. (Org.). O novo sindicalismo: vinte anos depois. Editora Vozes, Petrópolis, 1999.

PNAD CONTÍNUA: taxa de desocupação é de $12,2 \%$ e taxa de subutilização é de $24,4 \%$ no trimestre encerrado em março de 2020 . Agência de Notícias IBGE, 30 de abril de 2020. Disponível em: https://agenciadenoticias.ibge.gov.br/agencia-sala-de-imprensa/2013agencia-de-noticias/releases/27534-pnad-continua-taxa-de-desocupacao-e-de-12-2-e-taxa-de-subutilizacao-e-de-24-4-no-trimestreencerrado-em-marco-de-2020 Acesso em: 27 nov. 2020.

POCHMANN, M. Nova classe média? O trabalho na base da pirâmide social brasileira. São Paulo: Boitempo, 2012.

PRADO JUNIOR, C. Formação do Brasil Contemporâneo: Colônia. São Paulo: Companhia das Letras, 2011.

SILVA, M. A. da. Os reflexos da crise econômica sobre os direitos trabalhistas no Brasil. Revista Katálysis., Florianópolis, v. 22, n. 2, p. 252-272, maio/ago. 2019.

VALENTIN, E. C. do R. B; PERUZZO, J. F. A ideologia empreendedora: ocultamento da questão de classe e sua funcionalidade ao capitalismo. Temporalis, Brasília (DF), ano 17, n. 34, jul./dez. 2017, pp. 101-126.

\section{Rodrigo Fernandes Ribeiro}

rodrigo.fernandes@ufop.edu.br

Doutorado em Serviço Social pela Universidade Federal de Santa Catarina (UFSC)

Professor do Departamento de Serviço Social da Universidade Federal de Ouro Preto (UFOP)

\section{UFOP}

Instituto de Ciências Sociais Aplicadas

Rua do Catete, 166 - Centro

Mariana - Minas Gerais - Brasil

CEP: 35.420-000

\author{
Agradecimentos \\ Não se aplica. \\ Agência financiadora \\ Não se aplica. \\ Contribuições das autoras \\ Não se aplica.
}

\author{
Aprovação por Comitê de Ética e consentimento para \\ participação \\ Não se aplica. \\ Consentimento para publicação \\ Consentimento do autor. \\ Conflito de interesses \\ Não há conflito de interesses.
}

